\section{Political debate: science will be the loser}

\begin{abstract}
SIR — David Goldston appropriately demolishes the idea of a US presidential candidate debate on science, in his Column 'A debatable proposition' (Nature 451, 621; 2008). It's hard to imagine anything worse for the cause of science than to subject it to the sort of high-profile demagogic posturing now reserved for immigration, medical care, social security, the economic downturn and the war in Iraq. Science continues to enjoy a protected and privileged status in American politics, in no small part because of its absence from the national political stage - a fact that many science promoters stubbornly refuse to understand.

\section{Daniel Sarewit}

Consortium for Science, Policy and Outcomes, Arizona State University, Tempe,

Arizona 85287, USA
\end{abstract}

\section{Political debate: it is a risk, but one that's worth taking}

SIR - David Goldston in his Column 'A debatable proposition' (Nature 451, 621; 2008) questions the wisdom of a presidential debate on science and raises several issues that explain his scepticism. I am in favour of such a debate, but I urge the organizers of the petition calling for this, at www. Sciencedebate2008.com, to give thoughtful consideration to Goldston's points.

I believe the debate is important for several reasons. It will improve the public's understanding of the host of challenges faced by the new president, and by the rest of us in the United States, in areas such as health and medicine, energy and climate change, economic competitiveness and jobs, clean air and water, security, natural (and unnatural) disasters and many others. These will require the new knowledge and tools that stem from research and innovation, coupled with wise policy choices. The American people should expect their future president to understand and be able to articulate this coupling and how it relates to his or her priorities. And the candidates should see this as an opportunity to show the voters what visionary leadership in the twenty-first century is all about.

In framing the debate and developing specific questions for the candidates, the organizers should bear in mind some of the pitfalls that Goldston mentions. For example, understanding climate change and its probable impact on the planet and its people is a matter for science. But the challenge goes far beyond science and technology, even though taking steps to lessen the negative consequences will require scientific understanding and technology. It will involve political trade-offs that we in the science community might not want the public to associate with science. So there is a risk in holding such a debate. However, in my opinion, the risk is well worth taking.

\section{Neal Lane}

Department of Physics and Astronomy and James A. Baker III Institute for Public Policy, Rice University, Mail Stop 108, Box 1892, Houston, Texas 77251-1892, USA

\section{Government subsidized by academia on conservation}

SIR - Your Editorial 'The great divide' (Nature 450, 135-136; 2007) argues that conservation biologists should be more involved in conservation practice. Subsequent Correspondence (Nature 451, 127 ; 2008) suggests that this should be an integral part of the process in promotion and tenure of academic conservation biologists. In my view, this is frankly unrealistic.

Of course academic studies should inform practice, but this does not mean that academics should be practitioners. The suggestion that the value of a conservation biologist should be measured by what would have happened had that person not carried out their work, despite being almost impossible to evaluate, runs into the same problems as placing a value on any conservation activity. Should a UK institution, for example, promote a tropicalrainforest conservation biologist over a colleague who studies British moorland, or one who works on tiger conservation?

Academic research should be relevant to practice, but not practice-led. If we need to chase science that can be put into practice to demonstrate our effectiveness, conservation biology as a discipline will never move from being a reactionary science to dealing with issues of biodiversity conservation in a proactive manner. The fact is that universities have long been subsidizing efforts in the practice of nature conservation that should be made by governments and nongovernmental organizations.

The divide is one of personnel. Positions are needed for academically able and wellinformed practising conservationists within governmental agencies. In Britain, this has not been the case since the Nature Conservancy split from the Natural Environment Research Council in 1973. The efforts of those academics pushing for evidence-based conservation are an important step in the right direction, but a step that should have been taken by the government long ago.

Philip Wheeler

Centre for Environmental and Marine Sciences, University of Hull, Scarborough Campus, Filey Road, Scarborough YO113AZ, UK

\section{Celebrations for Darwin downplay Wallace's role}

SIR - We agree with Kevin Padian ('Darwin's enduring legacy' Nature 451, 632-634; 2008) that next year's Darwin anniversaries - the 200th anniversary of his birth and 150th anniversary of On the Origin of Species - should be celebrated enthusiastically. But few seem to be aware that this year marks the 150th anniversary of one of the greatest discoveries in the history of science: the theory of evolution by natural selection. Although this idea is often credited solely to Charles Darwin, it was independently discovered by naturalist Alfred Russel Wallace 150 years ago this month, while he was suffering from fever on the Indonesian island of Halmahera. Wallace sent Darwin an essay detailing the theory, which was published, together with two short excerpts from Darwin's unpublished writings on the subject, by the Linnean Society of London in August 1858.

Widespread preparations for the Darwin celebrations are now being made by the University of Cambridge and the Natural History Museum, among many others (see http://darwin-online.org.uk/2009.html and a Darwin walk at http://tinyurl.com/ysofwn). But to our knowledge, very little is being planned to celebrate the 150th anniversary of the discovery of natural selection. This contrasts with the lavish series of events and exhibitions that took place 50 years ago to celebrate the centenary of the discovery. The Linnean Society will host a modest event to commemorate the pre-publication reading on 1 July 1858 of Darwin and Wallace's seminal papers. Information is available from the Alfred Russel Wallace Memorial Fund (founded by G. W. B.) at www.wallacefund.info/2008-events.

This lack of interest in the 2008 anniversary is indicative of how Wallace's achievements have been overshadowed by Darwin's since Wallace's death in 1913, a process certainly not helped by the Darwin 'industry' of recent decades. During his lifetime, Wallace received plenty of recognition from his contemporaries for his part in the discovery, as indicated by the many honours bestowed on him. These include the Darwin-Wallace and Linnean Gold Medals (Linnean Society); the Copley, Darwin and Royal Medals (Royal Society); and the Order of Merit. Isn't it perhaps time for the current darwinocentric view of the history of biology to be revised?

George W. Beccaloni, Vincent S. Smith Entomology Department, The Natural History Museum, Cromwell Road, London SW7 5BD, UK

Contributions to this page may be sent to correspondence@nature.com. See Guide to Authors at http://tinyurl.com/373jsv. 